HEAD AND NECK

\title{
Predictors of recurrence after surgical treatment of idiopathic progressive subglottic stenosis
}

\section{Predittori di recidiva dopo trattamento chirurgico delle stenosi idiopatiche subglottiche progressive}

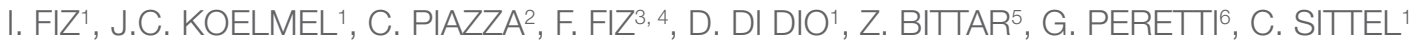 \\ ${ }^{1}$ Department of Otorhinolaryngology Head and Neck Surgery, Klinikum Stuttgart, Germany; ${ }^{2}$ Department \\ of Otorhinolaryngology, Maxillofacial and Thyroid Surgery, Fondazione IRCCS, National Cancer Institute of Milan, \\ University of Milan, Italy; ${ }^{3}$ Nuclear Medicine Unit, Department of Radiology, Uni-Klinikum Tuebingen, Germany; \\ ${ }^{4}$ Department of Internal Medicine, University of Genoa, Italy; ${ }^{5}$ Institute for Pathology, Klinikum Stuttgart, Germany; \\ ${ }^{6}$ Department of Otorhinolaryngology Head and Neck Surgery, University of Genoa, Italy
}

\section{SUMMARY}

Idiopathic progressive subglottic stenosis is a rare cause of tracheal narrowing. Partial cricotracheal resection and anastomosis can cure idiopathic stenosis, even if some patients may require multiple interventions and experience voice and swallowing deterioration. We investigated risk factors for retreatment and assessed the impact of crico-tracheal resection on functional parameters. We conducted a retrospective multicentric study on 44 female patients (mean age $52.6 \pm 13.1$ years) affected by idiopathic stenosis and treated by crico-tracheal resection between 2002 and 2016. Functional outcomes after crico-tracheal resection were assessed by the airway-dyspnoea-voice-swallowing score (range 1-5, with " 1 " expressing normal and "5" completely altered function). Previous treatments, grade of stenosis, site, airway comorbidities, age and resection length were tested as predictors of postoperative complications and number of additional treatments, using bivariate and multivariate analysis. The overall decannulation rate was $97.3 \%$. The dyspnoea score improved (mean variation $1.4 \pm 1.0 ; \mathrm{p}<0.001$ ), while voice and swallowing were negatively affected (mean variation $1.6 \pm 0.9$ and $0.5 \pm 0.7$, respectively; $\mathrm{p}<0.001$ ). Airway comorbidities were associated with a higher rate of complications $(\mathrm{p}<0.05)$. Retreatments were more frequent in patients with postoperative complications $(\mathrm{p}<0.05)$. The length of resection correlated with the number of subsequent treatments $(\mathrm{R}=0.52 ; \mathrm{p}<0.01)$. At multivariate analysis, post-operative complications were predicted by comorbidities and disease stage $(p<0.05)$; number of retreatments was linked to the length of resection $(p<0.05)$ as well as with the application of mitomycin $\mathrm{C}(\mathrm{p}<0.001)$. Crico-tracheal resection for idiopathic progressive subglottic stenosis offers good functional results in terms of airway patency. These data suggest that a higher complication rate can be expected in patients affected by comorbidities. Moreover, more extensive surgical resection seems to be associated with the occurrence and number of subsequent retreatments. On the contrary, the local application of an anti-proliferative drug does not seem to be of use in preventing recurrences.

KEY WORDS: Idiopathic subglottic stenosis • Partial cricotracheal resection • Complications • Recurrence

\section{RIASSUNTO}

La stenosi idiopatica subglottica progressiva rappresenta una rara causa di restringimento della laringe. La resezione parziale con successiva anastomosi può potenzialmente essere curativa; nonostante ciò alcuni pazienti richiedono un numero elevato di ritrattamenti e possono sviluppare disfonia e disfagia in seguito all'intervento. In questo studio abbiamo investigato i fattori di rischio per il ritrattamento e abbiamo valutato l'impatto della resezione crico-tracheale sui parametri funzionali. $\grave{E}$ stata condotta un'analisi multicentrica retrospettiva su 44 pazienti di sesso femminile (età media 52,6 \pm 13,1 anni), sottoposti a resezione crico-tracheale tra il 2002 e il 2016. Gli esiti funzionali sono stati valutati utilizzando la scala "vie aeree-dispnea-voce-disfagia" dove ognuno di questi parametri è stato valutato con un punteggio da 1 a 5 , ove 1 esprime una funzione normale e 5 una funzione completamente compromessa. L'esistenza di trattamenti pregressi, il grado di stenosi, il sito della stenosi, la presenza di comorbidità delle vie aeree, l'età e la lunghezza del segmento resecato sono stati testati all'analisi bivariata e multivariata come predittori di complicanze e di trattamenti aggiuntivi. Il trattamento ha permesso la decannulazione del paziente nel 97,3\% dei casi. L'indice di dispnea è migliorato (variazione media $1,4 \pm 1,0 ; p<0,001$ ), mentre quelli relativi alla voce e alla deglutizione sono peggiorati (variazione media 1,6 $\pm 0,9$ and 0,5 $\pm 0,7$, rispettivamente; $p<0,001$ ). I pazienti affetti da comorbidità delle vie aeree hanno presentato un tasso più alto di complicanze $(p<0,05)$. La lunghezza del segmento resecato ha dimostrato una correlazione diretta con il numero dei ritrattamenti $(R=0,52 ; p<0,01)$. All'analisi multivariata, le complicazioni post-operatorie erano predette dall' esistenza di comorbidità e dallo stadio di malattia ( $p<0,05)$; il numero dei ritrattamenti era associato alla lunghezza del tratto resecato $(p<0,05)$ e all'applicazione di Mitomicina $C(p<0,001)$. La resezione crico-tracheale offre dei buoni risultati funzionali per la cura della stenosi idiopatica subglottica progressiva, in termini di pervietà delle vie aeree. I nostri dati suggeriscono che i pazienti affetti da comorbidità possono presentare un'incidenza più alta di complicazioni. Inoltre, resezioni chirurgiche più estese sembrano essere associate all'incidenza e al numero dei ritrattamenti. Al contrario, l'applicazione di sostanza anti-proliferativa non sembra essere utile nella prevenzione delle recidive.

PAROLE CHIAVE: Stenosi idiopatica subglottica $\bullet$ Resezione cricotracheale parziale $\bullet$ Complicazioni $\bullet$ Recidiva

Cite this article as: Acta Otorhinolaryngol Ital 2018;38:417-423. http://dx.doi.org/10.14639/0392-100X-1872

(C) Società Italiana di Otorinolaringologia e Chirurgia Cervico-Facciale 


\section{Introduction}

Idiopathic progressive subglottic stenosis (IPSS) is a rare, acquired cause of upper airway related dyspnoea, whose pathologic hallmark is represented by progressive scarring of the subglottic larynx and upper trachea. Even though its pathogenic mechanisms remain obscure, onset of IPSS has been linked with severe coughing, gastrooesophageal reflux disease (GERD) or to autoimmune inflammatory mechanisms. These mechanisms have been proposed as possible triggers of an inflammatory process that is later sustained by unclear mechanisms ${ }^{1-4}$. Moreover, a distinctive hallmark of IPSS is represented by its almost exclusive predilection for peri-menopausal women, with a median age of 47 years ${ }^{5}$. Respiratory distress usually has an insidious onset, but it eventually progresses from exertional dyspnoea to respiratory symptoms even at rest and stridor. The disease shows usually a slow but constant progression and all patients eventually require surgical treatment to restore respiratory function and quality of life ${ }^{467}$. Different surgical options have been advocated for IPSS management, ranging from endoscopic to openneck approaches ${ }^{4-8}$. Recent studies seem to favour the latter, as laryngotracheal reconstruction techniques have shown better long-term results and lower recurrence rates compared with transoral surgery ${ }^{69-13}$. In fact, patients treated by endoscopic balloon dilatation alone needed to be repeatedly treated to maintain functional airway patency ${ }^{7}$; this leads to a negative impact on the overall quality of life, without attaining proper cure ${ }^{14}$. Similar results have been observed by CO2 laser-assisted IPSS resection ${ }^{15}$. Conversely, partial cricotracheal resection and anastomosis (PCTRA) can potentially achieve complete and permanent restoration of airway function ${ }^{5}$.

However, a significant percentage of patients show multiple relapses, even in case of apparent total resection of the affected segment ${ }^{78}$. In light of this, we investigated the risk factors for post-operative complications and re-operation in IPSS treated by PCTRA as well as the impact of the procedure on functional parameters such as breathing, phonation and swallowing in a large multicentre series of subjects managed by a common therapeutic strategy.

\section{Materials and methods}

\section{Patient population}

We retrospectively analysed clinical data of 44 female patients (mean age 52.6 years; range 31-79) affected by IPSS and treated by PCTRA at the Department of Otorhinolaryngology, Katharinenhospital, Stuttgart, Germany between July 2010 and June 2016 and in the Departments of Otorhinolaryngology Head and Neck Surgery, Universities of Brescia and Genoa, Italy between June 2002 and August 2014. The inclusion criteria were: no history of intubation at least 2 years before symptoms onset, no previous tracheotomy, no concurrent head and neck trauma, airway infection, or systemic autoimmune diseases.

All patients signed a written informed consent form, which was reviewed and approved by the respective local Ethics Committees and included the utilisation of anonymised patient data for research purposes.

\section{Endoscopic work-up}

The endoscopic evaluation included a detailed static and dynamic analysis of the airways ${ }^{16}$. Pre-operative assessment was performed under direct laryngoscopy, in spontaneous ventilation using $0^{\circ}$ and $30^{\circ}$ rigid telescopes (Karl Storz, Tuttlingen, Germany) to examine passive vocal fold mobility, as well as the precise stenosis site and its craniocaudal extension. Subsequently, adequate laryngeal exposure in microlaryngoscopy was obtained with different laryngoscopes such as the Sataloff (Microfrance ${ }^{\circledR}$ iXomed, Saint Aubin Le Monial, France), Dedo or Dedo-Ossoff (Pilling, Philadelphia, PA, USA) to precisely evaluate and measure the extension, consistency and grade of IPSS. A biopsy was always performed to rule out an autoimmune background of the disease process.

\section{Operative technique}

In all patients, PCTRA was performed as a single-stage surgical procedure aimed at treating stenosis of the subglottic larynx and trachea by complete resection of the affected airway segment, including the anterior cricoid arch, the mucosal layer of the cricoid plate potentially up to the cricoarytenoid joints and, when needed, the first tracheal ring(s) in order to reestablish its continuity in a single step by thyro-crico-tracheal anastomosis ${ }^{17}$. At the end of the procedure, all patients were primarily extubated and then monitored at in an intensive care unit.

\section{Functional outcomes, complications frequency and need for retreatment after PCTRA}

Functional outcomes were assessed with the AirwayDyspnoea-Voice-Swallowing score (ADVS) ${ }^{18}$. This scale consists of 4 functional domains, including airway (A), dyspnea (D), voice (V), and swallowing (S). All parts of the scoring system have a 1 to 5 ordinal progressive scale, with " 1 " expressing normal and " 5 " completely impaired function. This scoring was obtained before and after intervention.

Variables including previous treatments, grade and localisation of IPSS, airway comorbidities, age and resection 
length were all tested as predictors of post-operative complications and number of additional treatments needed to cure the patient.

\section{Statistical analysis}

A T-test for paired samples was used to compare pre- and post-operative ADVS scores between patients. Correlation of previous treatments, grade and localisation of IPSS, airway comorbidities, age and resection length with post-operative complications and number of additional treatments was tested by bivariate analysis using Pearson's product-moment correlation coefficient index. Significant correlations were then inserted and tested using a multivariate model (MANOVA). A p value $<0.05$ was considered statistically significant. The SPSS program (SPSS, v. 21.0, IBM, Armonk NY, USA) was used for statistical analysis.

\section{Results}

\section{Clinical outcomes after PCTRA}

The operation-specific decannulation rate following PCTRA was $97.3 \%$, resulting in a permanent tracheostomy in one patient due to a major post-operative complication. However, 6 subjects (13.6\%) were submitted to post-operative temporary tracheotomy (mean duration 9.3 days; range 2-18), because of serious complications ( 2 oedema, 1 haematoma, 2 tracheal necrosis and 1 inversion of vocal fold motility), which arose 5-17 days after the intervention (median $=11$ days).

This, however, had no influence on the airway score $(1.12 \pm 0.5$ before PCTRA vs $1.12 \pm 0.5$ after PCTRA, Fig. 1). The dyspnoea score improved significantly $(2.89 \pm 0.72$ before PCTRA vs $1.45 \pm 0.66$ after PCTRA; $\mathrm{p}<0.001$, Fig. 1), as most of patients showed significant improvement in symptoms. In fact, no patient presented post-operative resting dyspnoea.

On average, voice was negatively affected in all patients $(1.34 \pm 0.71$ before PCTRA vs $2.91 \pm 0.42$ after PCTRA; $\mathrm{p}<0.001$, Fig. 1), as the majority of patients passed from slight or absent voice problems to post-operative dysphonia due to cricothyroid muscles and cricoid arch resection with ensuing loss of vocal pitch modulation. As a result, most subjects experienced significant difficulties in being heard or understood in loud environments.

Similarly, swallowing scores were negatively affected $(1.11 \pm 0.32$ before PCTRA vs $1.57 \pm 0.73$ after PCTRA; $\mathrm{p}<0.001$, Fig. 1). After surgery, the majority of patients showed the onset of mild subjective swallowing difficulties even though they were able to eat a normal diet, in comparison to intact swallowing prior to surgery.

\section{Post-operative complications}

Notably, all patients affected by airway comorbidities (asthma, chronic obstructive pulmonary disease, unilateral vocal

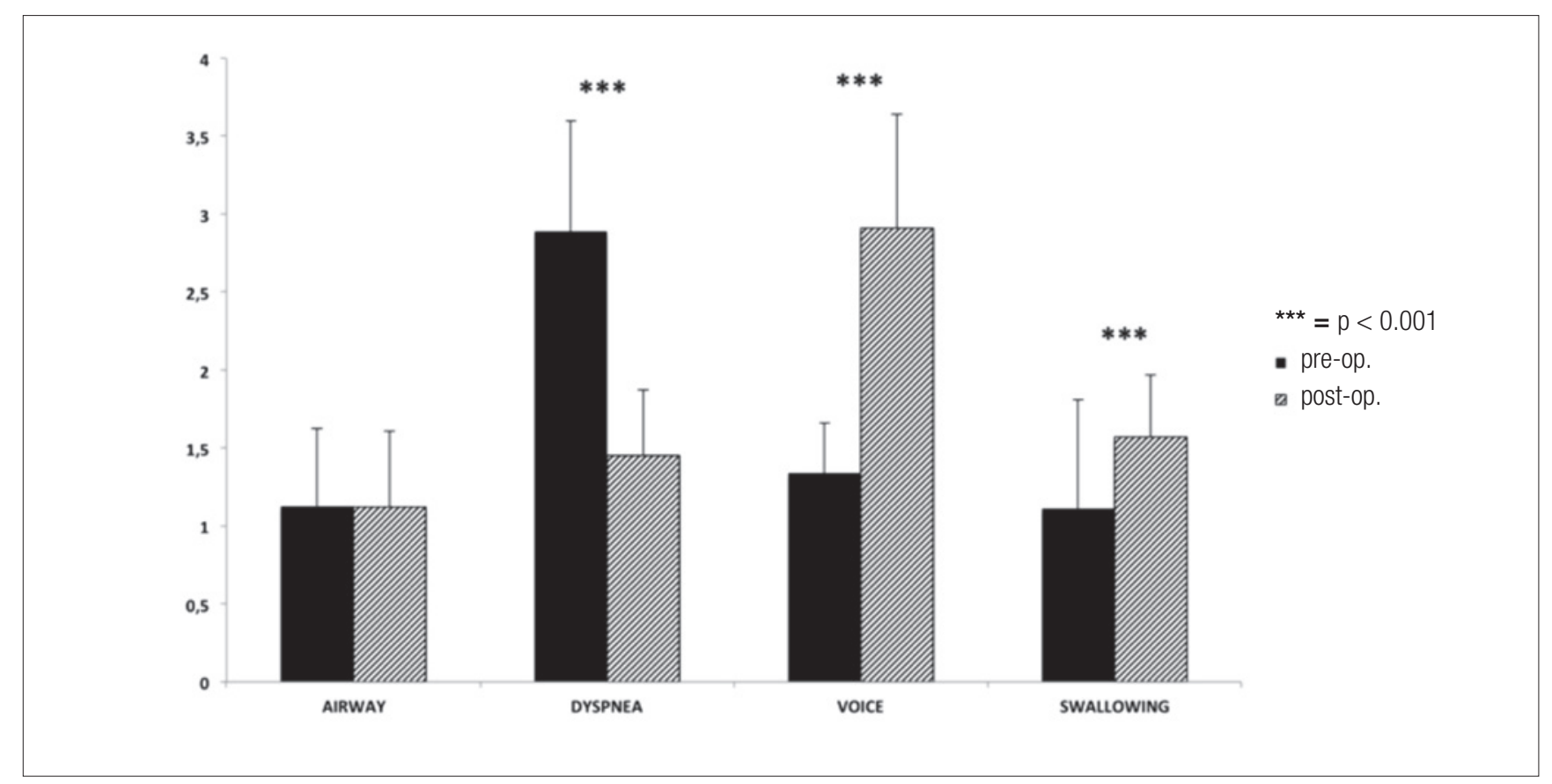

Fig. 1. Pre- and post-operative ADVS scores. While airway scores were unaffected by the surgical procedure, subjective dyspnoea improved significantly. However, this came at the cost of a relative deterioration in voice and swallowing scores. 
fold palsy) encountered post-operative complications. By contrast, adverse events occurred in $52.6 \%$ of patients without pre-existing airway conditions $(\mathrm{p}<0.05 v s$ the remaining patients). The most commonly observed post-operative complication was laryngeal oedema, affecting 12 (27.3\%) patients, and resulting in short-term orotracheal intubation in 5 cases, endoscopic removal of fibrin tissue or injection of triamcinolone acetonide (Volon A, Dermapharm AG) in 5, endoscopic balloon dilatation in one and short-term tracheotomy in one. Three (6.8\%) subjects experienced post-operative cervical emphysema followed by anastomotic revision in 2 cases and short-term orotracheal intubation in one. Cervical haematoma occurred in 4 patients $(9.1 \%)$, and required neck surgical re-exploration in 2 . The most severe observed complication, in the form of tracheal necrosis, occurred in $4(9.1 \%)$ patients, resulting in temporary endoluminal tracheal stent in one case, temporary tracheotomy in 2 and permanent tracheotomy in another. Unilateral vocal cord paralysis occurred in $2(4.5 \%)$ subjects, and was managed by intracordal injection of Calcium Hydroxyapatite (Radiesse, Merz Aesthetics) in both cases. Temporary bilateral vocal fold paresis occurred in only one (2.3\%) patient and was treated by a reversible endoscopic unilateral arytenoid lateropexy according to Lichtenberger's technique ${ }^{19}$. See Figure 2 for details.

\section{Additional treatments}

Twenty-six $(59.1 \%)$ patients required additional endoscopic treatments (mean $3.2 \pm 2.3$; range 1-9), but no further open-surgical procedure. The endoscopic revisions included balloon dilatations (Inspira Air Technology, Acclarent) and topical injection of triamcinolone acetonide in 9 cases, and balloon dilatation with topical application of mitomycin C ( $2 \mathrm{mg} / \mathrm{ml}$ for 2 minutes) in 12 cases. Granulation tissue was removed in 11 subjects. See Figure 3 for details. Retreatments were significantly more frequent in patients who presented post-operative complications $(2.2 \pm 1.7$ vs $3.7 \pm 2.5$; $\mathrm{p}<0.05)$. Moreover, length of resection directly correlated with the number of subsequent treatments $(R=0.52 ; p<0.01$, Fig. 4). Topical application of mitomycin $\mathrm{C}$ did not improve the clinical outcome; on the contrary, patients receiving mitomycin $\mathrm{C}$ had to be re-treated more frequently compared with those who did not $(4.1 \pm 3$ vs $1.1 \pm 1.7 ; \mathrm{p}<0.001)$. This finding was independent from clinical stage as well as from length of resected segments.

\section{MANOVA}

At multivariate analysis, onset of post-operative complications was predicted by the presence of pre-operative comorbidities (RR 7.2; $<<0.05$ ) as well by disease stage $(R R=5.1$, respectively; $p<0.05)$. Conversely,

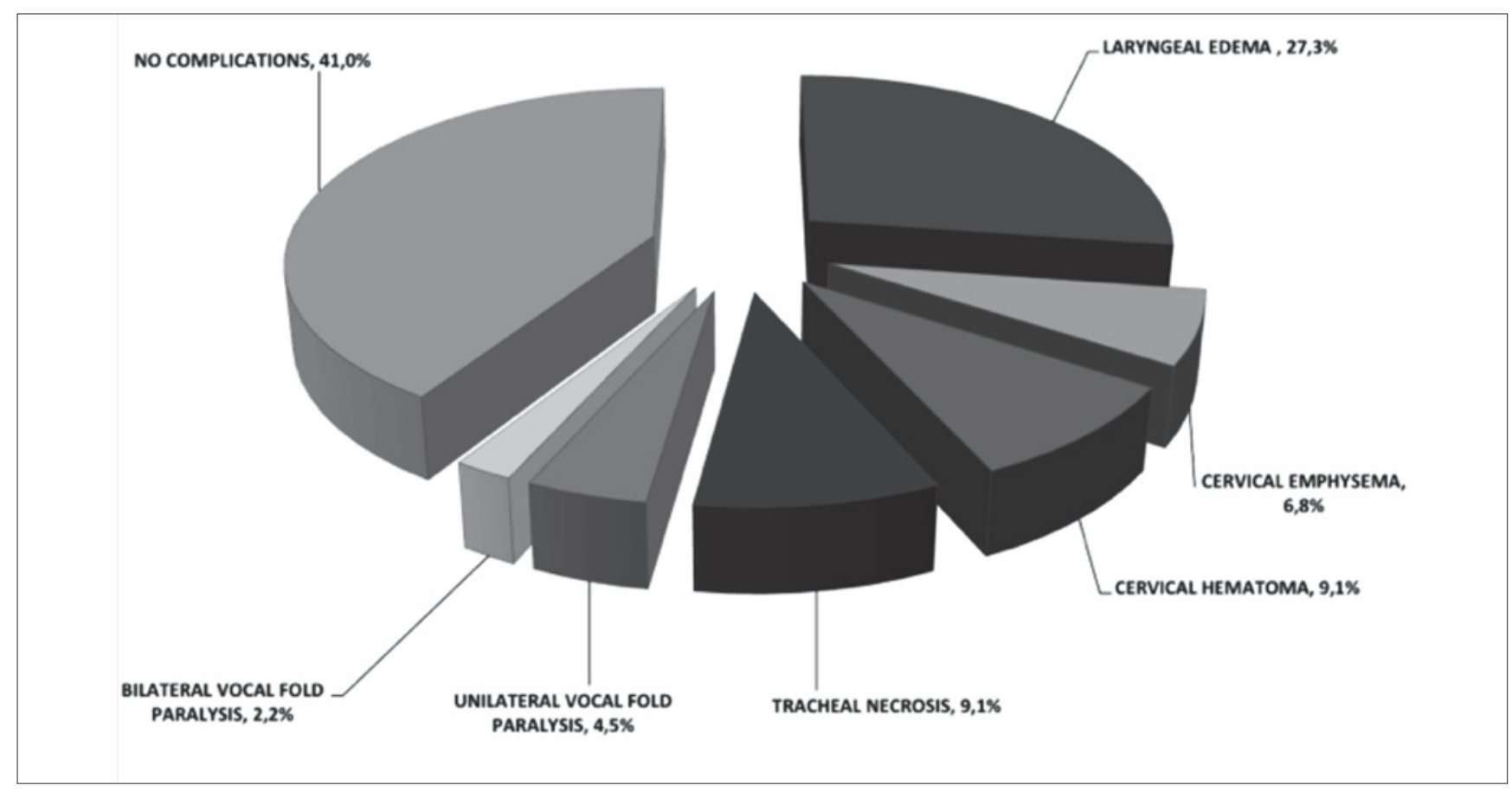

Fig. 2. Post-operative complications. Most patients suffered from complications following crico-tracheal surgery. However, most of these complications were mild and reversible; only one patient suffered long-term damage. 


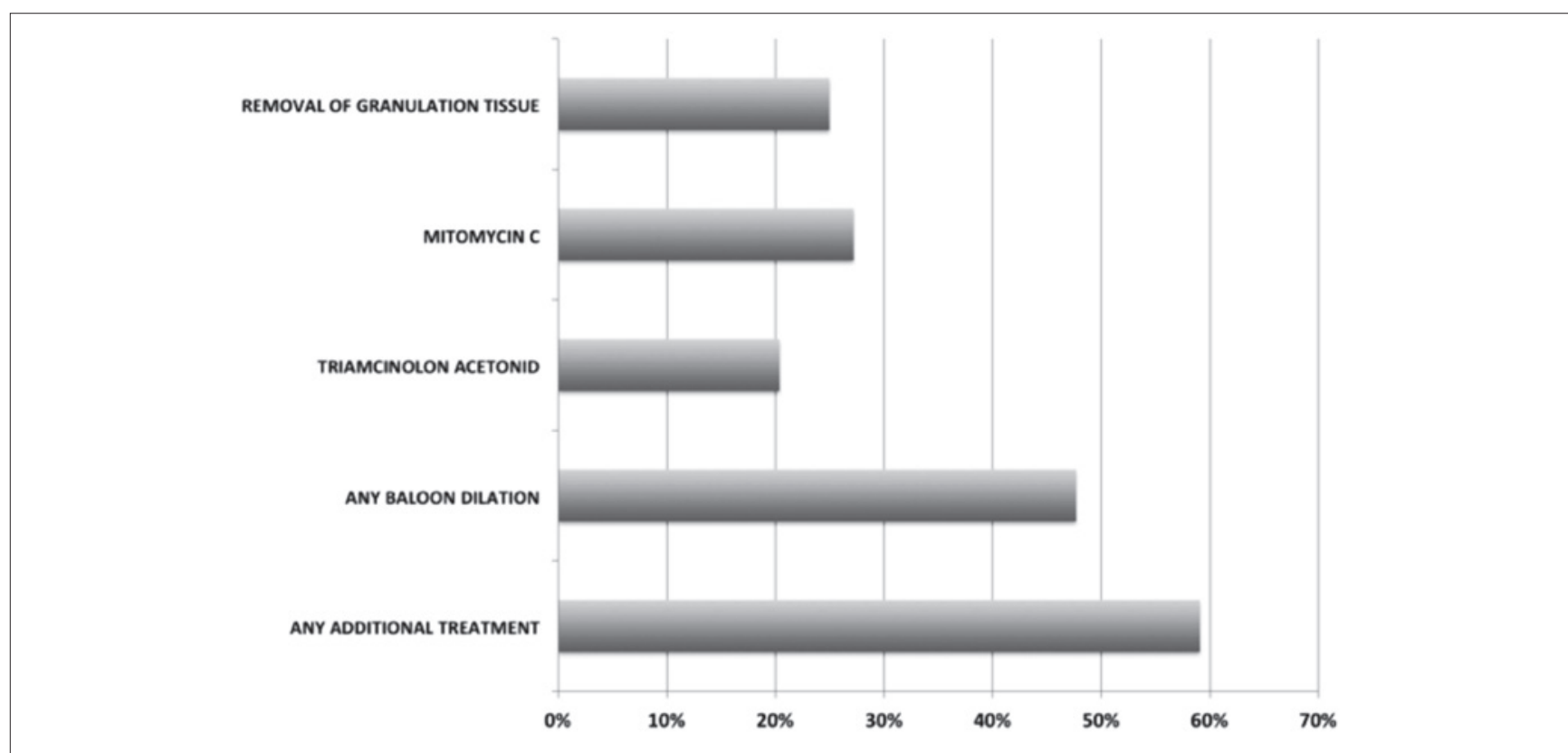

Fig. 3. Frequency of retreatments. None of the patients required re-intervention with open surgery. However, endoscopic treatments were necessary in about half of patients. Local application of anti-proliferative drugs produced no appreciable effect.

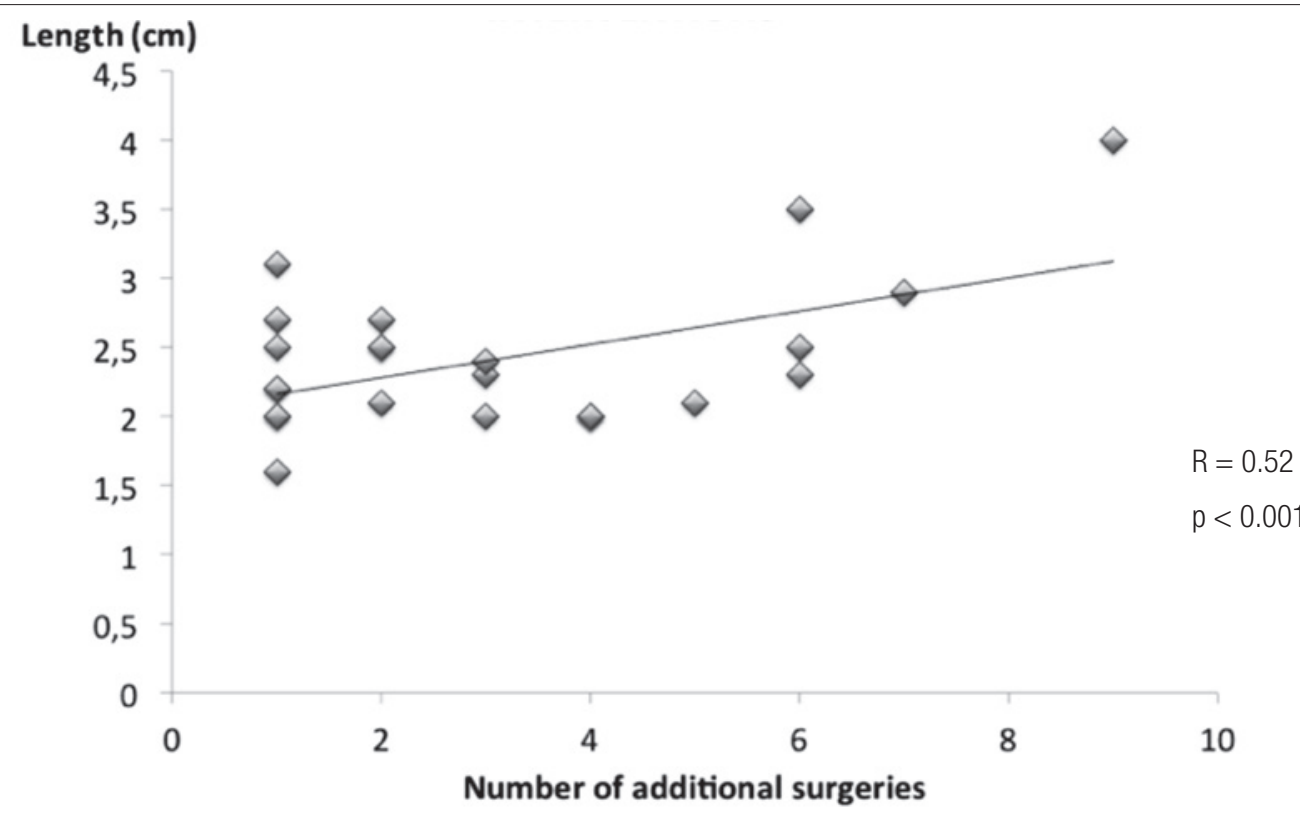

Fig. 4. Correlation between length of resection and number of re-interventions. Longer resections were associated to recidivating stenosis, perhaps implying that a more extensive resection is more likely to trigger further inflammatory reactions.

history of previous treatment did not influence the surgery outcome.

Clinical stage at baseline and history of previous surgeries did not predict the need or the number of additional procedures. However, number of subsequent retreatment was predicted by the length of resected segment $(R R=2.4$; $\mathrm{p}<0.05)$.

Regarding functional outcomes, the length of the resected segment was strongly associated with the post-operative subjective dyspnoea score $(\mathrm{p}<0.01)$. 
Application of mitomycin $\mathrm{C}$ was directly and strongly associated with occurrence of retreatments $(p<0.001)$ as well as with the number of additional surgical procedures $(\mathrm{p}=0.001)$.

\section{Discussion}

The present research confirms that the success rate for PCTRA is extremely high, similar to previous series ${ }^{5}$. However, it also highlights that successful decannulation can come through this technique at a cost. In fact, patients were relieved of dyspnoea, but their phonatory and swallowing function were negatively affected. Moreover, there was a significant percentage of patients in which the stenosis recurs. Actually, when compared to other stenosis aetiologies, IPSS patients have longer duration of symptoms and a tendency to require multiple treatments ${ }^{2021}$. In fact, idiopathic stenosis appears to be sustained by a chronic inflammatory syndrome, at least partially dependent on hormone receptor unbalance ${ }^{20-22}$; in IPSS, surgery may thus alleviate the symptoms, but not fully remove the underlying cause.

Nonetheless, our data help to shed light on the reasons underlying the tendency to relapse. In fact, it appears that pre-operative presence of any type of airway comorbidities may set the stage for the insurgence of post-operative complications, which in turn could promote the tendency to relapse. A greater size of the removed segment can also increase the risk of recurrence, other than possibly affecting negatively the chance of dyspnoea improvement. Even though fully eliminating the affected segment and maintaining a safe resection margin is the objective of the PCTRA procedure, the available data suggests that IPSS is an abnormal inflammatory reaction triggered by an unapparent stimulus ${ }^{23-25}$. In this context, treatment with PCTRA may per se constitute a trigger, capable of inducing an inflammatory response in a previously unaffected (but otherwise susceptible) airway segment. In longer resections, force applied to the suture margins, as well as wider and lengthier tissue manipulation could negatively impact the repair process and constitute a stimulus for the abovementioned inflammatory reaction. This reasoning could also explain the inefficacy of the adjuvant local application of mitomycin, in accordance with the recent literature ${ }^{26}$. Actually, patients treated with this drug presented a worse outcome, which does not seem to be dependent on selection bias (as the mitomycin subgroup had neither a higher stage nor a greater prevalence of comorbidities), but could be rather linked to respiratory epithelium damage following local mitomycin application as well as to impaired wound healing and fibrin accumulation ${ }^{27}$.

Given these considerations, the occurrence of voice and swallowing deterioration, the longer post-operative recovery and the higher risk of complications linked with PTCRA, the surgeon may be tempted to favor an endoscopic treatment. However, the best possibility for cure lies in the first surgery, as the patient can expect better long-term results in terms of airway stability and patency. Moreover, patients operated by endoscopic procedures will have to face more treatments and generally worse long-term outcomes. However, patients with a relatively high risk of perioperative complications, active airway comorbidities and in whom deterioration of the phonatory and swallowing functions is not acceptable could receive greater benefits from an endoscopic approach, embracing PCTRA only after multiple failed transoral attempts or worsening of airway problems. It is then of utmost importance to thoroughly counsel the patient about intra- and post-operative risks and complications, including the possibility of additional endoscopic treatments and/or revision procedures ${ }^{5}$. Moreover, patients should be warned about the frequent alterations of voice, which are more likely to occur when an open procedure is employed. In fact, they should be reassured that they will have a functional voice, but some changes may be noticed in comparison with pre-operative function.

This study has some intrinsic limitations: it is a retrospective evaluation of patients treated at three different centres over a prolonged period of time. However, diagnostic work-up, treatment philosophy, surgical technique, instrumentation and follow-up policy were comparable. Moreover, follow-up time was variable, as some patients treated in the early 2000s stopped attending visits after a long remission period and, conversely, some patients were recruited at relatively recent times. Finally, evaluation of functional parameters was based on the self-reported symptoms' heftiness. This evaluation was selected so as to avoid bias due to different calibration and availability of instrumentation in the three different centers. This could have caused difference in symptoms reporting; however, no statistically significant variations were detected among the scores in the three subgroups.

\section{Conclusions}

Surgical treatment by PCTRA is effective in treating IPSS; however, life-long surveillance is necessary as the majority of patients will experience disease relapse during the course of follow-up. Accurate evaluation of the clinical history and careful assessment of airway related comorbidities are of great value in predicting, reducing, and properly managing perioperative complications, as well as the occurrence of relapse, in IPSS. The goals of PCTRA should be the restoration of airway physiologic patency, while reducing to 
a minimum voice and swallowing-related sequelae and the complication rate. At present, this approach remains of special relevance in management of IPSS and the one that allows the highest rates of both short and long-term success.

\section{Conflict of interest statement}

None declared.

\section{References}

1 Damrose EJ. On the development of idiopathic subglottic stenosis. Med Hypotheses 2008;71:122-5.

2 Peña J, Cicero R, Marin J, et al. Laryngotracheal reconstruction in subglottic stenosis: an ancient problem still present. Otolaryngol Head Neck Surg 2001;125:397-400.

3 Gnagi SH, Howard BE, Anderson C, et al. Idiopathic subglottic and tracheal stenosis: a survey of the patient experience. Ann Otol Rhinol Laryngol 2015;124:734-9.

4 Giudice M, Piazza C, Foccoli P, et al. Idiopathic subglottic stenosis: management by endoscopic and open-neck surgery in a series of 30 patients. Eur Arch Otorhinolaryngol 2003;260:235-8.

5 Wang H, Wright CD, Wain JC, et al. Idiopathic subglottic stenosis: factors affecting outcome after single-stage repair. Ann Thorac Surg 2015;100:1804-11.

6 Sittel C. Idiopathic progressive subglottic stenosis. Laryngorhinootologie 2014;93:474-81.

7 Kocdor P, Siegel ER, Suen JY, et al. Comorbidities and factors associated with endoscopic surgical outcomes in adult laryngotracheal stenosis. Eur Arch Otorhinolaryngol 2016;273:419-24.

8 Costantino CL, Mathisen DJ. Idiopathic laryngotracheal stenosis. J Thorac Dis 2016;8(Suppl 2):S204-9.

9 Grillo HC. Management of idiopathic tracheal stenosis. Chest Surg Clin N Am 1996;6:811-8.

10 Pearson FG. Idiopathic laryngotracheal stenosis. J Thorac Cardiovasc Surg 2004;127:10-1.

11 Ashiku SK, Kuzucu A, Grillo HC, et al. Idiopathic laryngotracheal stenosis: effective definitive treatment with laryngotracheal resection. J Thorac Cardiovasc Surg 2004;127:99-107.

12 Pearson FG, Brito-Filomeno L, Cooper JD. Experience with partial cricoid resection and thyrotracheal anastomosis. Ann Otol Rhinol Laryngol 1986;95:582-5.

13 Gelbard A, Donovan DT, Ongkasuwan J, et al. Disease homogeneity and treatment heterogeneity in idiopathic subglottic stenosis. Laryngoscope 2016;126:1390-6.
14 Gallo A, Pagliuca G, Greco A, et al. Laryngotracheal stenosis treated with multiple surgeries: experience, results and prognostic factors in 70 patients. Acta Otorhinolaryngol Ital 2012;32:182-8.

15 Maldonado F, Loiselle A, Depew ZS, et al. Idiopathic subglottic stenosis: an evolving therapeutic algorithm. Laryngoscope 2014; 124:498-503.

16 Monnier P, Dikkers FG, Eckel H, et al. Preoperative assessment and classification of benign laryngotracheal stenosis: a consensus paper of the European Laryngological Society. Eur Arch Otorhinolaryngol 2015;272:2885-96.

17 Piazza C, Del Bon F, Paderno A, et al. Complications after tracheal and cricotracheal resection and anastomosis for inflammatory and neoplastic stenosis. Ann Otol Rhinol Laryngol 2014;123:798-804.

18 Nouraei SA, Sandhu GS. Outcome of multimodality approach to the management of idiopathic subglottic stenosis. Laryngoscope 2013;123:2474-84.

19 Lichtenberger G. Reversible lateralization of the paralyzed vocal cord without tracheostomy. Ann Otol Rhinol Laryngol 2002;111:21-6.

20 Mark EJ, Meng F, Kradin RL, et al. Idiopathic tracheal stenosis: a clinicopathologic study of 63 cases and comparison of the pathology with chondromalacia. Am J Surg Pathol 2008;32:1138-43.

21 Cui P, Chen W. Treatment of idiopathic laryngotracheal stenosis with laryngotracheal reconstruction. J Laryngol Otol 2009;123:1233-6.

22 Fiz I, Bittar Z, Piazza C, et al. Hormone receptors analysis in idiopathic progressive subglottic stenosis. Laryngoscope 2018;128:E72-E77.

23 Jindal JR, Milbrath MM, Shaker R, et al. Gastroesophageal reflux as a likely cause of 'idiopathic' subglottic stenosis. Ann Otol Rhinol Laryngol 1994;103:186-91.

24 Blumin JH, Johnston N. Evidence of extraesophageal reflux in idiopathic subglottic stenosis. Laryngoscope 2011;121:1266-73.

25 Stone JH. Wegener's granulomatosis etanercept trial research group. Limited versus severe Wegener's granulomatosis: baseline data on patients in the Wegener's granulomatosis etanercept trial. Arthritis Rheum 2003;48:2299-309.

26 Aarnæs MT, Sandvik L, Brøndbo K. Idiopathic subglottic stenosis: an epidemiological single-center study. Eur Arch Otorhinolaryngol 2017;274:2225-8.

27 Hirshoren N, Eliashar R. Wound-healing modulation in upper airway stenosis-myths and facts. Head Neck 2009;31:111-26.

Address for correspondence: Ivana Fiz, Department of Otorhinolaryngology Head and Neck Surgery, Klinikum Stuttgart, Kriegsbergstrasse 60, 70174 Stuttgart, Germany. Tel. +49 1623181 826. Fax + 49071127833 209. E-mail: ivana.fiz.orl@gmail.com 